\title{
Overview of Polymers for Improved Oil Recovery Treatments
}

\section{Introduction}

High water production in oil and gas wells reduces significantly the recovery factor. Mechanical as well as chemical methods are applied to shut-off water productive zones. Crosslinked polymers showed high efficiency to seal off water zones in high permeability sandstone and fractured carbonate reservoirs. Moreover, emulsified polymeric formulations have been introduced for deep profile modification by changing the wettability of the rock and hence allowing selective plugging of water.
Estimation of IOR potential in a British reservoir

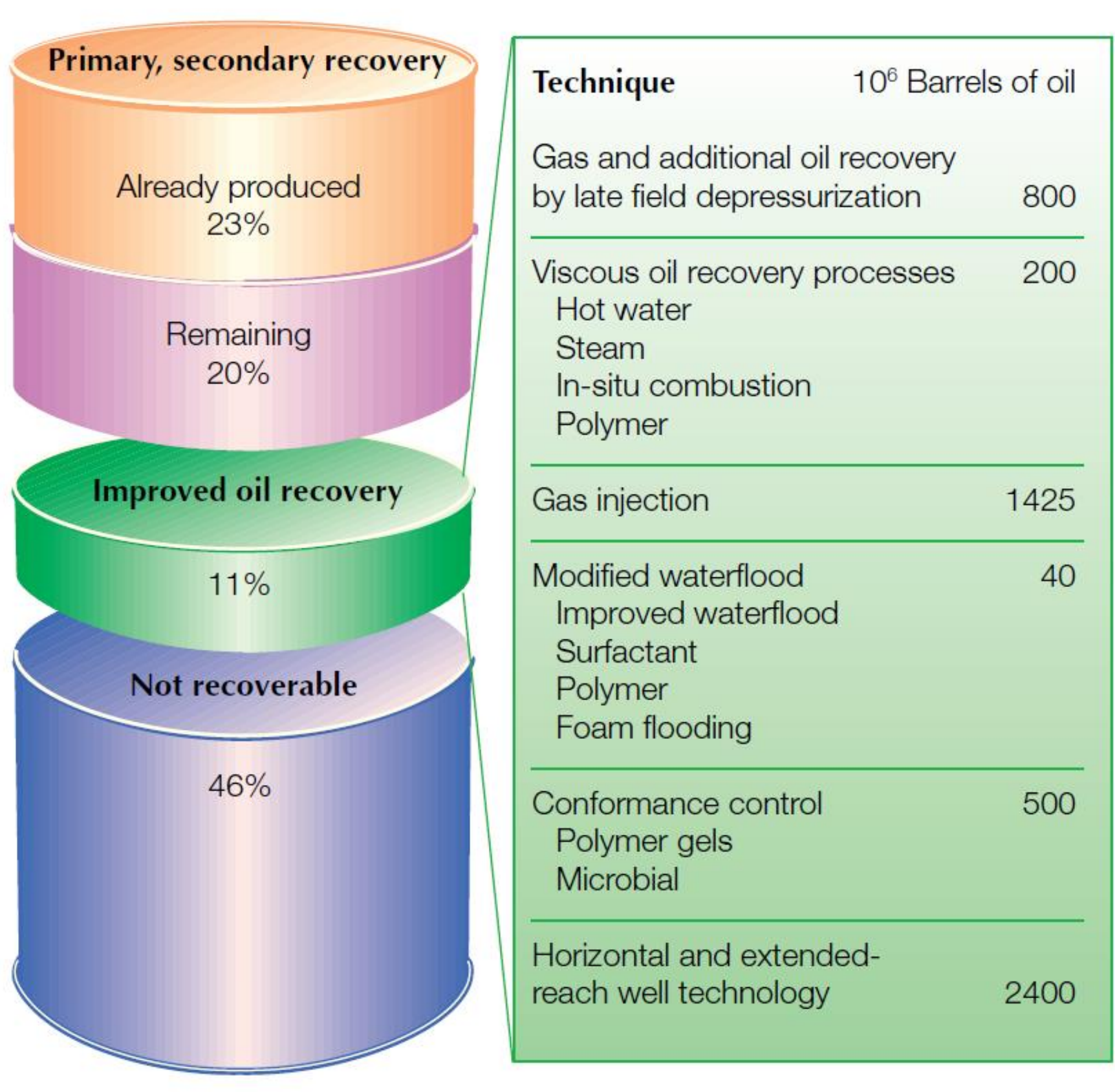

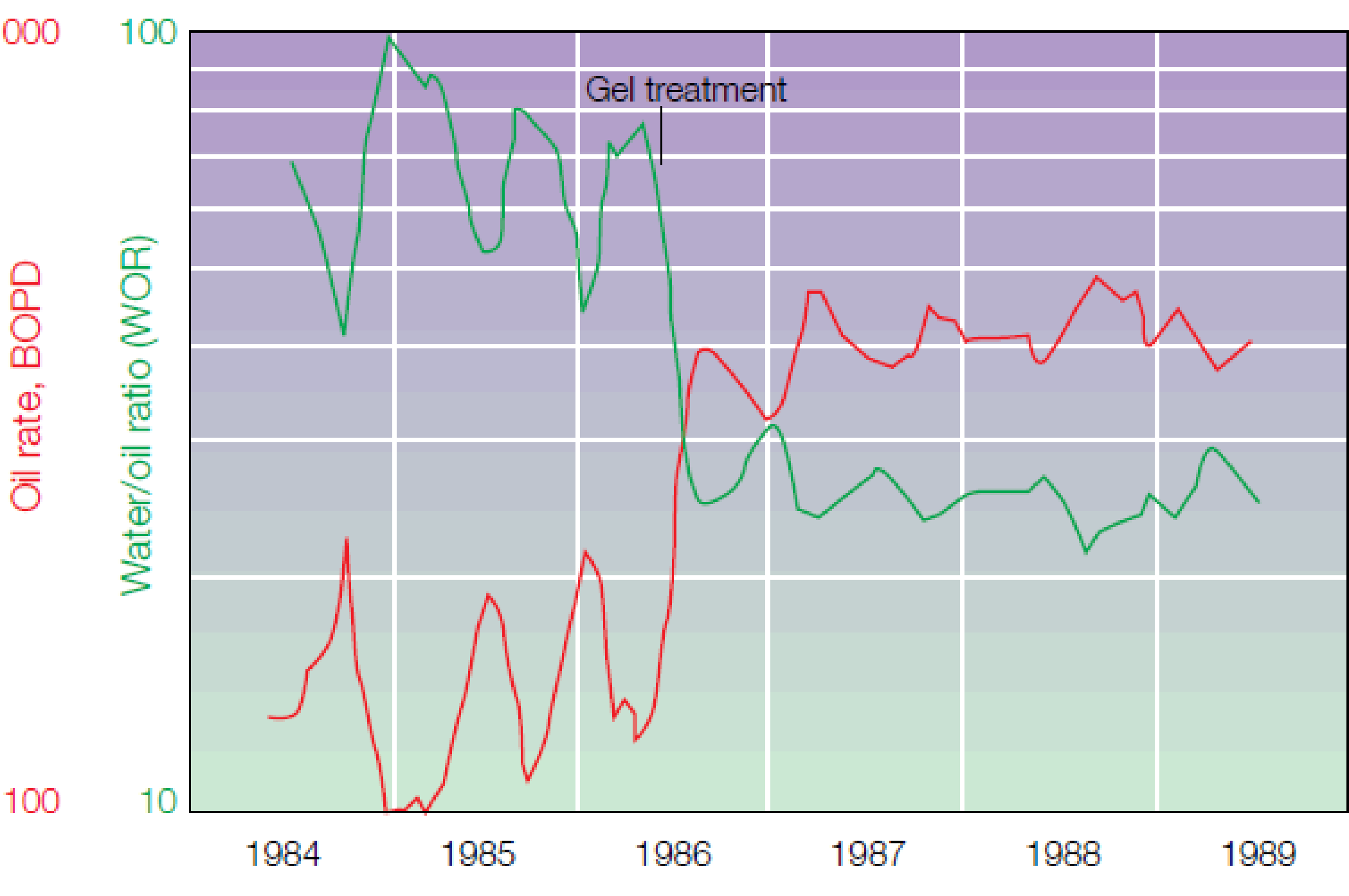

$\square$ Example on gel treatment effect in a reservoir operated by Marathon Oil Company

\section{Method of Application}

Water production can result from several reasons. Thus, characterizing the reservoir and understanding its geology is essential before choosing the best conformance control method.
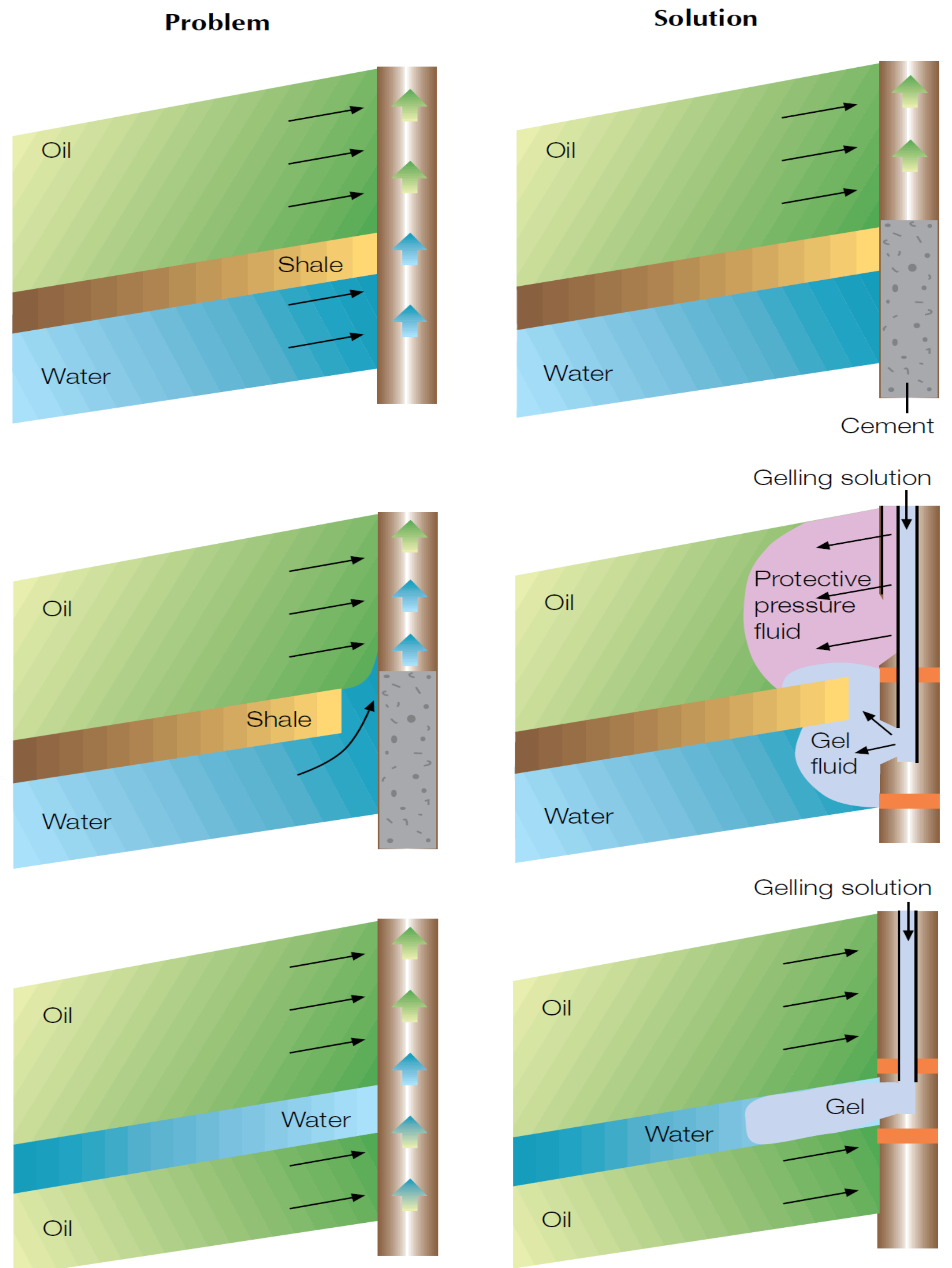

Multiple Cases for water-control applications

Gelling materials are injected as liquid solutions, where it crosslink and solidifies after reaching the designated zone. Therefore it is essential to understand the factors affecting the main responses which are gelation time and final gel strength.

Factors affecting the gelation behavior:

\section{Crosslinking Chemistry}
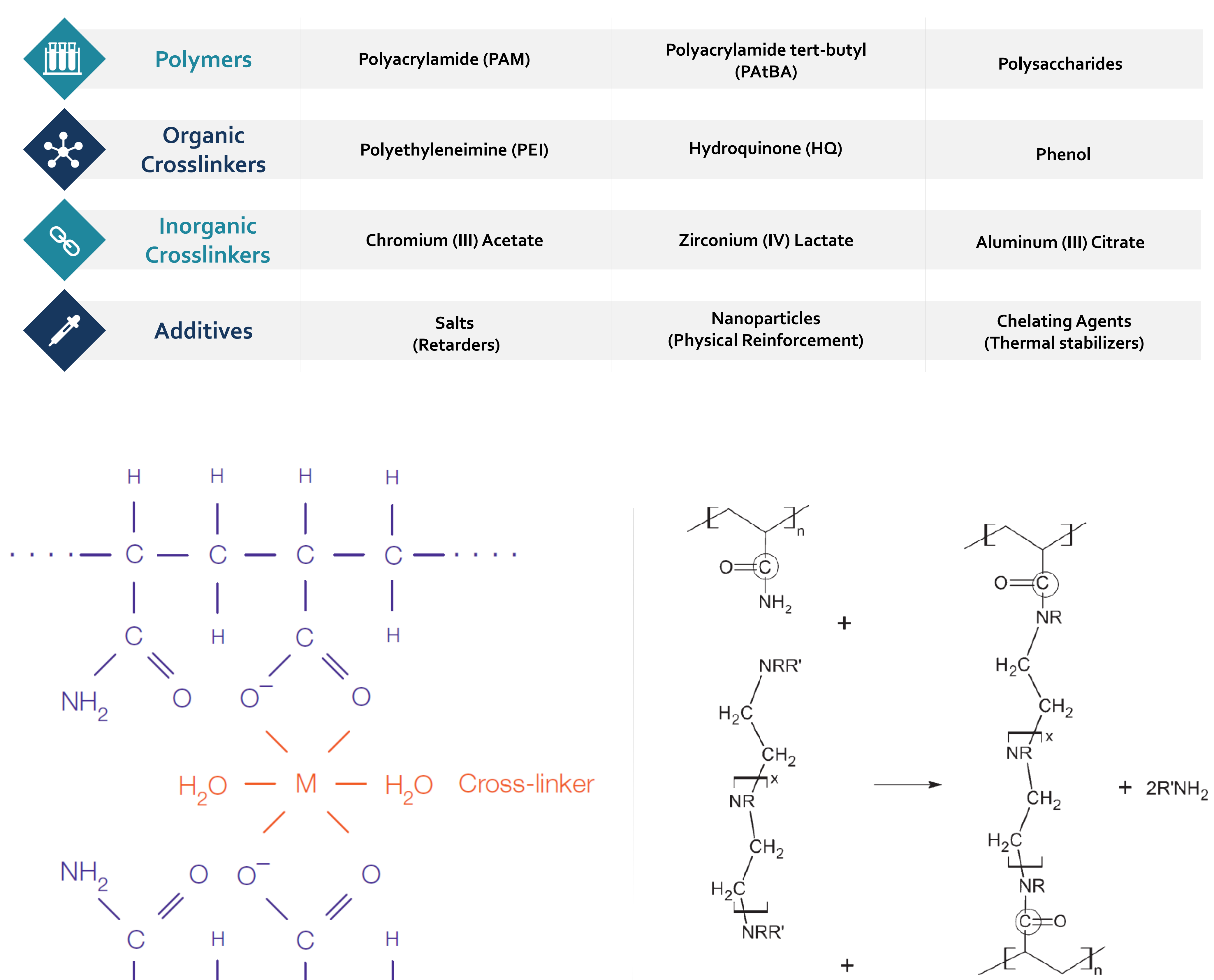

$=0$

Mechanism of inorganic crosslinking where $M$ is metallic ion applied in low temperature reservoirs $\left(<80^{\circ} \mathrm{C}\right)$

Mechanism of organic crosslinking (PAM/PEI) applied in high temperature reservoirs $\left(>80^{\circ} \mathrm{C}\right)$

\section{Results \& Conclusions}

Field application reviled that organically crosslinked gels breaks two months after placing in high temperature reservoirs $\left(130^{\circ} \mathrm{C}\right)$. Therefore, nano-silica is used in this study as a physical reinforcing agent to increase the shear resistivity of mature gels.

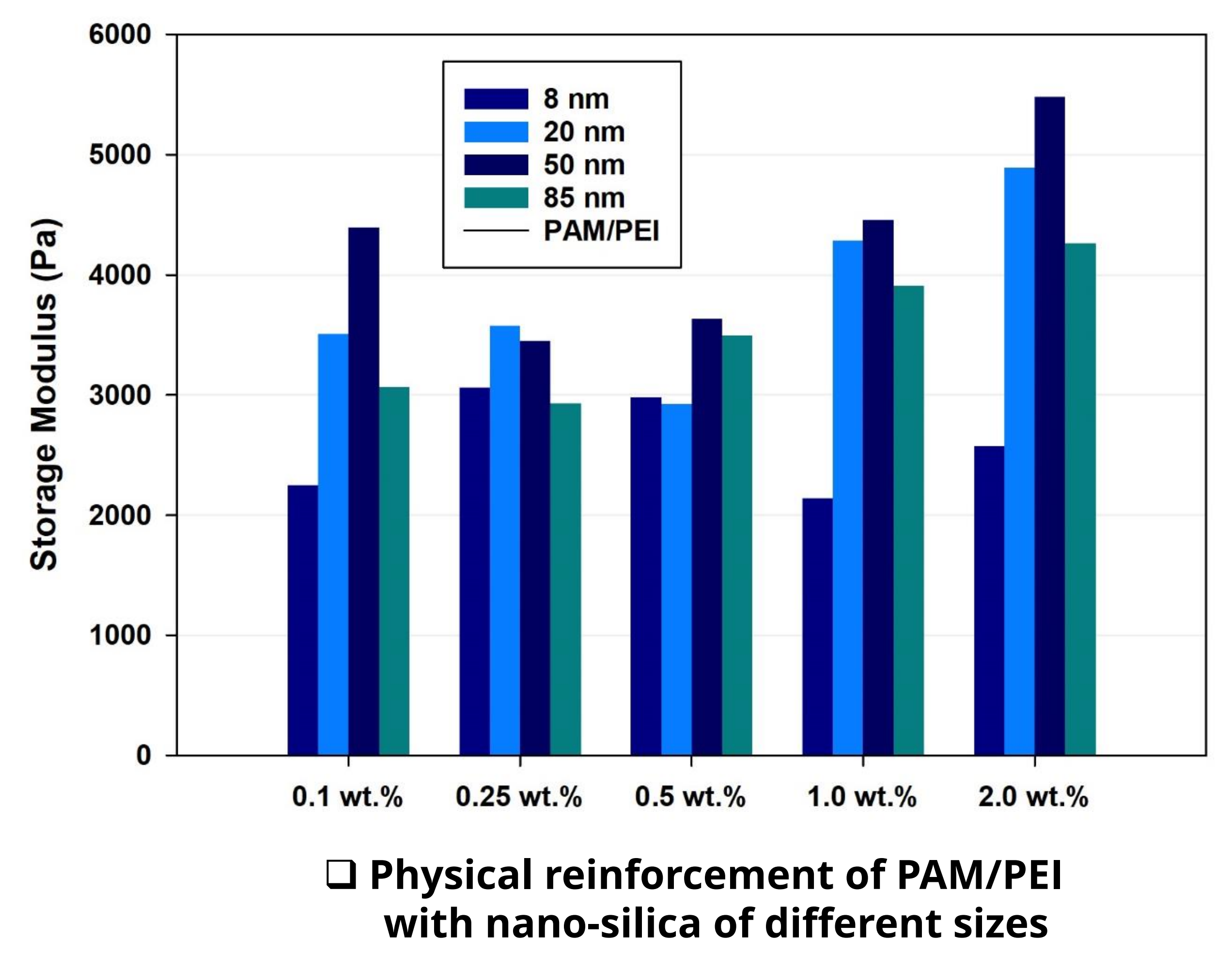

Therefore, nanosilica proved to be a good strengthening agent being able to increase the storage modulus by more than 200\%. Nano-silica with the size $50 \mathrm{~nm}$ was found to be optimum, which has been attributed to the most physical stability in liquid solutions.

Silica can then serve as a thermal stabilizer to enhance and increase the lifetime of gels in oil reservoirs as well as it provides the strength needed to withstand the continuous shear and the harsh conditions.

\section{Publications}

-A. Hamza, I.A. Hussein, M. Shamlooh, M.S. Nasser, M. Magzoub, S. Salehi, Polymeric Gels for Oil and Gas Conformance Control Applications and Methods of Making Same, US PATENT 62/880,845, 2019. Provisional Application.

-Shamlooh, M.,, Hamza, A., Hussein, I.A.,, Nasser, M.S., Magzoub, M., Salehi, S., 2019. Investigation of the Rheological Properties of Nanosilica-Reinforced PAM /PEI Gels for Wellbore Strengthening at High Reservoir Temperatures. Energy \& Fuels.

and Salehi, S., 2019. Polymeric formulations used for loss circulation materials oil and gas wells: A review.

-Shamlooh, M., Hamza, A., Hussein, I.A., Nasser, M.S., Salehi, S., 2019. Gelation Kinetics of Functionalized Silica Crosslinked Polymeric Gels used in Conformance Control Applications. Journal of thermal Analysis and Calorimeter. Under Review. •Hamza, A., Shamlooh, M., Hussein, I.A., Nasser, M., Salehi, S., 2019. Rheology of Triamine Functionalized Silica Reinforced Polymeric Gels developed for Conformance Control Applications. Energy and Fuel. Under Review. 